\title{
Osteosynthesis of Intracapsular Femoral Neck Fracture by Cannulated Hip Screws
}

\author{
Mohammad Mahbubur Rahman Khan, ${ }^{1}$ Md. Samiul Islam, ${ }^{2}$ Abdul Khaleque, ${ }^{3}$ Rabin Chandra Halder ${ }^{4}$
}

\begin{abstract}
Introduction: The reduction and fixation of femoral neck fractures within 12 hours is considered optimal. However, studies have reported insufficient fracture reduction, rather than surgical fixing time, is a predictor of complication. In our country, patients attend tertiary care facilities late, ranging from days to even weeks; hence 12 hours principle is frequently violated. The present study assessed the outcomes of surgically treated femoral neck fracture with cannulated cancellous hip screws within two weeks of the injury.

Methods: This prospective study observed 19 patients with traumatic intracapsular femoral neck fracture aged between 18 to 60 years and injury to surgery time up to 2 weeks. For the fixation of the neck, three standard cannulated screws $(7.3 \mathrm{~mm}$ cancellous) were inserted according to the "3 Point Principle". Data regarding demographic variables, baseline variables of fracture personality, and outcomes variables were recorded. The final outcome was sassed according to Harris Hip Score. The relation between the duration of fixation and the final outcome was analyzed.

Result: 19 patients with femoral neck fractures were included in the study. The mean age of the 19 patients was $36.58 \pm 11.93$ years, with $16(84.21 \%)$ of them from the male gender. The minimum duration from injury to operation time was 2 days, and the maximum duration was 13 days. Among 19 patients mean duration was 6.58 days with SD $= \pm 2.99$ days. $73.6 \%$ of the cases had the surgery within 7 days of sustaining the injury. According to Harris Hip Score, $17(89.60 \%)$ of the cases had a satisfactory outcome. The relationship of final outcome with injury to operation time was not statistically significant $(p=0.421)$. This means there was no difference in Harris Hip Score between operations done early or late.
\end{abstract}

Conclusion: The time interval from injury to surgery did not influence the functional outcome. Cannulated screw fixation is a viable option in treating femoral neck fracture.

TAJ 2021; 34: No-2: 122-128

\section{Introduction}

Fracture of the neck of the femur is one of the common difficult problems over the world, at all ages and at all races. It is yet a great challenge to orthopedic surgeons and unsolved fractures as far as treatment and result are concerned. ${ }^{1}$ It has been recognized that the treatment of this fracture is essentially surgical, and operative treatment should not be withheld except under the most exceptional circumstances. Fracture neck of femur is most common in a geriatric group of people over 60 years old, especially in postmenopausal ladies (80-85\%); still, many occur at any age and 
in any sex. ${ }^{2}$ Due to peculiarity of blood supply to head and neck of femur, this fracture is commonly complicated by non-union and avascular necrosis of femoral head. Result following this injury depends on several factors, such as (a) age, (b) time of injury, (c) extent of injury, (d) adequacy of reduction, (e) rigidity of fixation, (f) proper postoperative management. ${ }^{3}$

It is said that early reduction and joint decompression and fixation correct the kinking of retinacular vessels, reduce intracapsular pressure, and increases the chance of restoring maximum blood supply to the head and neck. As the head and neck have no periosteum, no soft tissue attachment, and are always bathed by synovial fluid, the probability of callus formation is almost nil, which are the drawbacks in the success of treatment of fracture neck of femur. ${ }^{1}$ All these problems can be solved by primary prosthetic replacement of the femoral head in older people, but in the young age group where anatomical restoration and stability of the femoral head and neck is desirable. The treatment options are: (1) cannulated cancellous screw fixation, (2) dynamic hip screw fixation, and (3) rigid fixation and muscle pedicle bone graft.

The most widely used method now a day advocates treating fracture neck of the femur by cannulated cancellous hip screws, which give compression and rigid fixation at the fracture site. The sliding hip screw (SHS) is an alternative for basicervical femoral neck fracture. ${ }^{4}$ The reduction and fixation of a femoral neck fracture within 12 hours are considered optimal. It has been asserted that stabilization after 24 hours is related to worse outcomes and a higher frequency of surgical failure. ${ }^{5}$ However, another study evaluated surgery for femoral neck fracture within 3 to 18 days and concluded, in femoral neck fractures, the time between the occurrence of the injury and surgical fixation is not linked to the development of complications. Rather, inadequate fracture reduction is a predictive factor for complications in these fractures. ${ }^{6}$ In our country, $85 \%$ of the total population lives in rural areas, and due to illiteracy, poor socioeconomic condition, and underdeveloped communication facilities, patients attend tertiary care facilities late, ranging from days to even weeks. As a result, it is not possible to comply with the fundamental concept of timing of fracture fixation. The present study, conducted at a tertiary care orthopaedic referral hospital, assessed the outcomes of surgically treated femoral neck fracture with cannulated cancellous hip screws fixation within two weeks of the injury.

\section{Materials and Methods}

This prospective study observed 19 patients with traumatic intracapsular femoral neck fracture aged between 18 to 60 years and injury to surgery time up to 2 weeks admitted to the National Institute of Traumatology and Orthopaedic Rehabilitation (NITOR), Dhaka, from June 2018 to December 2019. For the fixation of the neck, three standard cannulated screws $(7.3 \mathrm{~mm}$ cancellous) were inserted according to the "3 Point Principle". 7 Patient with septic focus, major injuries to chest, abdomen, pelvis, and head or multiple fractures, pathological fracture of the femoral neck and patients not fit for general anesthesia were excluded. According to the revised Declaration of Helsinki, appropriate informed written consent was obtained from each patient. The protocol was accepted by the Ethical and Scientific Committee of the National Institute of Traumatology and Orthopaedic Rehabilitation (NITOR).

A pre-formed structured questionnaire form was used containing demographic variables (age, sex, occupation), baseline variables (Fracture configuration and interval between injury and fixation), Outcomes variables (Fracture union time and rate, Postoperative complications such as pain, infection, fracture malalignment, implant failure, range of movement of hip and knee, limb length discrepancy, gait abnormality including limp, support, distance walked, sitting, enter public transportation, climbing stairs, put $\mathrm{n}$ shoes and socks and final Outcome- According to Harris Hip Score). Data were collected by interview, observation, clinical examination, and radiological findings. Data were processed and analyzed using SPSS 23.0 (Statistical Package for Social Science). For all analytical tests level of significance was set at 0.05 . 


\section{Results}

During the study period, a total of 19 patients with femoral neck fractures were included in the study to evaluate the outcome of fixation with cannulated cancellous screws. The youngest patient in the current research was 20 years old, and the oldest was 55 years. The majority were in between 20 to 39 years. The mean age of the 19 patients was $36.58 \pm 11.93$ years, with $16(84.21 \%)$ of them from the male gender. $26.32 \%$ of them were businessmen, $26.32 \%$ were service holders, $15.79 \%$ were students, $15.79 \%$ were housewives, $10.52 \%$ were farmers, and $05.26 \%$ case was day-laborer. Regarding the cause of injury $10(52.6 \%)$ patients gave the history of road traffic accident, 6(57.8\%) of the cases had a history of fall from standing height, and 2 cases sustained fall from height. The neck of femur fractures was classified according to the Garden stage. In our study, displaced femoral neck fracture (i.e., Garden Stage III and IV) accounted for $69 \%$, whereas undisplaced cases (i.e., Garden Stage I and II) accounted for $31 \%$ of all cases [Table 1]. The minimum duration from injury to operation was 2 days, and the maximum duration was 13 days. Among 19 patients mean duration was 6.58 days with $\mathrm{SD}= \pm 2.99$ days. $73.6 \%$ of the cases had the surgery within 7 days of sustaining the injury. The majority of these patients spent between 5 and 9 days in the hospital following their surgery. The mean postoperative hospital stays among 19 patients was $9.89 \pm 4.14$ days. In our research, all the cases showed radiological evidence of union within 20-24 weeks except 1 case of non-union, which was the only case of postoperative infection among the 19 patients. Limb shortening of $>1 \mathrm{~cm}$ were encountered in 2(10.5\%) cases. However, according to Harris Hip Score 17(89.60\%) of the cases had a satisfactory outcome. [Table 2]. When describing the Harris Hip Score broadly, $68.4 \%$ had an excellent outcome, $21.20 \%$ had a good outcome, and there was $1(5.2 \%)$ case each in the fair and bad categories [Figure 1]. The relationship of final outcome with injury to operation time was not statistically significant $(\mathrm{p}=0.421)$. [Table 4].

Table 1: Basic characteristics of the patients $(n=19)$

\begin{tabular}{lccc}
\hline Characteristics & Group & Mean \pm SD & $\mathrm{n}$ \\
\hline Age (in years) & $20-29$ & & $7(37)$ \\
& $30-39$ & $36.58 \pm 11.9$ & $4(21)$ \\
& & 3 & \\
& $40-49$ & $3(16)$ \\
& $50-59$ & $5(26)$ \\
\hline Sex & Male & $16(84.2)$ \\
& Female & $03(15.7)$ \\
\hline Occupation & Business & $05(26.3)$ \\
& Service & $05(26.3)$ \\
& Student & $03(15.7)$ \\
& Housewife & $03(15.7)$ \\
& Farmer & $02(10.5)$ \\
Cause of & Day laborer & $01(5.2)$ \\
Injury & Fall from standing & $6(57.8)$ \\
& height & \\
& Fall from height & $2(10.5)$ \\
& Road Traffic Accident & $10(52.6)$ \\
Classification & Others & $1(5.2)$ \\
(Garden type) & I & $1(5.2)$ \\
& II & $5(26.3)$ \\
& III & $5(26.3)$ \\
& IV & $8(42.1)$ \\
\hline
\end{tabular}


Values are presented as frequency, percentage, and mean \pm Standard Deviation (SD), the percentage in the parenthesis.

Table 2: Characteristics and Outcome of Surgical intervention $(n=19)$

\begin{tabular}{|c|c|c|c|}
\hline Characteristics & Group & Mean \pm SD & $\mathrm{n}$ \\
\hline \multirow[t]{2}{*}{ Injury to operation time (days) } & $0-7$ & $6.58 \pm 2.99$ & $14(73.6)$ \\
\hline & $>7$ & & $5(26.3)$ \\
\hline \multirow{4}{*}{$\begin{array}{l}\text { Post-operative hospital stay } \\
\text { (days) }\end{array}$} & $5-9$ & & $12(63.1)$ \\
\hline & $10-14$ & $9.89 \pm 4.14$ & $4(21.0)$ \\
\hline & $15-19$ & & $2(10.5)$ \\
\hline & $20-24$ & & $1(5.2)$ \\
\hline \multirow[t]{3}{*}{ Status of union } & United & & $7(36.8)$ \\
\hline & Delayed union & & $11(57.8)$ \\
\hline & Non-union & & $01(5.26)$ \\
\hline \multirow[t]{5}{*}{ Union time (weeks) } & $<12$ & & $7(36.8)$ \\
\hline & $12-15$ & & $3(17.7)$ \\
\hline & $16-19$ & $16.63 \pm 5.37$ & $6(31.5)$ \\
\hline & $20-24$ & & $2(10.5$ \\
\hline & Non union & & $1(5.2)$ \\
\hline \multirow{4}{*}{ Postoperative complications } & No complication & & 10 \\
\hline & Infection & & $1(5.26)$ \\
\hline & $\begin{array}{c}\text { Limb shortening }<1 \\
\mathrm{~cm}\end{array}$ & & $6(31.6)$ \\
\hline & $\begin{array}{c}\text { Limb shortening }>1 \\
\mathrm{~cm}\end{array}$ & & $2(10.5)$ \\
\hline \multirow{2}{*}{$\begin{array}{l}\text { Final outcomes (As per Harris } \\
\text { Hip Score) }\end{array}$} & ${ }^{\mathrm{a}}$ Satisfactory & & $17(89.60)$ \\
\hline & ${ }^{\mathrm{b}}$ Not satisfactory & & $2(10.40)$ \\
\hline
\end{tabular}

Values are presented as frequency, percentage, and mean \pm Standard Deviation (SD), the percentage in the parenthesis.

As per Harris Hip Score: ${ }^{a}$ Satisfactory $=$ Excellent + Good, ${ }^{b}$ Not satisfactory $=$ Fair + Poor 
Table 3: Relationship of final outcome with injury to operation time

\begin{tabular}{lccccc} 
Characteristics & \multicolumn{2}{c}{$\begin{array}{c}\text { Injury to operation time } \\
\text { (0-7 days) }\end{array}$} & $\begin{array}{c}\text { Injury to operation time } \\
\text { (> 7 days) }\end{array}$ & $p$ value \\
\cline { 2 - 5 } & $\mathrm{n}$ & $\%$ & $\mathrm{n}$ & $\%$ & \\
\cline { 2 - 5 } Outcome & 13 & 68.4 & 4 & 21.0 & $0.421^{\mathrm{ns}}$ \\
Satisfactory & 01 & 5.2 & 1 & 5.2 & \\
Not satisfactory & 01 & & & & \\
\hline
\end{tabular}

ns: none significant, value obtained by $X^{2}$-test

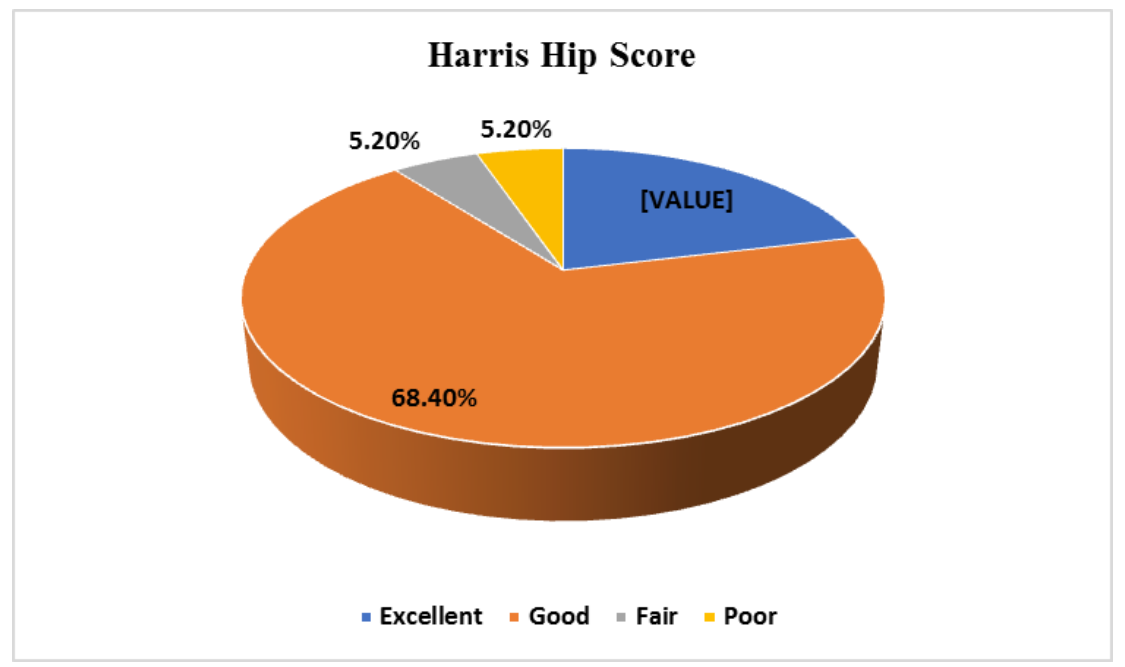

Figure1: outcome according to Harris Hip Score

\section{Discussion}

Fractures of the femoral neck remain a challenge in the clinical practice of orthopaedic surgeons. It is still a subject of debate over the years with regards to its management. Generally, the accepted mode of treatment is an internal fixation by a closed reduction in younger patients and patients without degenerative changes in the hip joint. The stable anatomical reduction can be achieved by means of three standard cannulated screws (7.3mm cancellous) inserted according to the "3 Point Principle" . ${ }^{7}$ In this study, we did close reduction and internal fixation by cannulated screws (7.0 mm cancellous) according to 3-point principle.
Our 19 patients range in age from 21 to 55 years old, with an average age of 36.58 years. The most common age range was 20-29 years (37\%), followed by 30-39 years (21\%). From 1975 to 1981, a similar study was done in Harborview Medical Centre, Seattle by Swiontkowski et al. (1984), where the mean age was 32.4 years (12-49 years). ${ }^{2}$ Like all trauma cases, femoral neck fracture in young is more common in males due to more activities and traveling. In a study of Operative treatment of femoral neck fractures in patients between the ages of fifteen and fifty years by Haidukewychet al, (2004), out of eighty-two patients, fifty-three patients were male, and twenty-nine were female. ${ }^{8}$ In our study, out of 19 patients, 16 were from the male gender. Femoral 
neck fracture occurs in younger patients, frequently as a result of high-energy trauma due to road traffic accidents, which was the main cause of these fractures seen in our study similar to a study at Mayo Clinic, Rochester, Minnesota by Haidukewych et al. (2004). ${ }^{8}$ In the current study, the majority (69\%) of fractures belonged to displaced (i.e., Garden Stage III and IV) group and undisplaced (i.e. Garden Stage I and II) cases were only in less than one-third cases, which is similar to the study in Esbjerg Central Hospital, Denmark by Frandsen et al. (1998). ${ }^{9}$

Urgent reduction and stable fixation of femoral neck fracture within less than six hours after the injury have been shown to reduce the risk of avascular necrosis (Jain, Koo, Kreder, 2002). ${ }^{10}$ But in our country, we did not receive most of the patients immediately after injury. In our series, out of 19 patients, we could operate only one patient at 2 days after injury; maximum duration was 13 days following injury; mean duration was 6.58 \pm 2.99 days. The two most challenging complications of femoral neck fractures in young adults to deal with are femoral head osteonecrosis and non-union. Radiological evidence of osteonecrosis will develop at a later period; at least 2 years are required to develop (Ly and Swiontkowski, 2008). ${ }^{11}$ This was beyond our follow-up period; hence we could not comment on osteonecrosis. However, we encountered 1 case of non-union, which was the only case of postoperative infection among the 19 patients. Chan, Ng, and Merican (2013) reported non-union is a well-recognized complication of femoral neck fractures. ${ }^{12}$ In our case, the mean union time was 16.63 weeks with $\mathrm{SD}= \pm 5.377$. Similar results were observed in the study of Kainth et al. (2011) where the meantime to union was 17 (range, 1230) weeks. ${ }^{13}$

Haidukewych et al. (2004) showed postoperative complications include pneumonia, wound infection and delayed closure, deep venous thrombosis, sepsis, urinary tract infection, ileus, thrombocytopenia, and atrial fibrillation. ${ }^{8}$ In our study, we found fewer postoperative complications included wound infection and mild limb length shortening. This may be due to the majority of the patients in our series were from the younger population. In this series, Harris Hip Score was used for outcome assessment, 16 patients $(84.2 \%)$ had excellent, and 3 patients $(15.8 \%)$ had a good functional outcome. A similar outcome was also achieved in a study conducted by Zhou, Tan, and Xu (2007) using Harris Hip Score ${ }^{14}$. We compared the functional outcome (according to Harris Hip Score) with the duration from injury to operation, where the operation was done within 7 days and more than 7 days. Here the result was statistically insignificant. This means there was no difference in Harris Hip Score between operations done early or late.

Our study had several limitations, the number of subjects was only 19 , and the operating surgeons were not the same in all cases, which renders the operator-dependent variation to some extent. The most common complication of fracture neck of femur is avascular necrosis, which develops after few years of the fracture. In this short follow-up period, we were unable to evaluate avascular necrosis. Nevertheless, the relationship between time interval to surgery and outcome was an important aspect of our research.

\section{Conclusion}

In our 19 months' experience in treating neck of femur fracture with closed reduction and cannulated screw fixation, we found excellent and good functional outcomes. The time interval from injury to surgery did not influence the functional outcome. Thus, cannulated screw fixation remains a viable option of treatment for the neck of femur fracture.

\section{Acknowledgment}

The authors express their gratitude to the institute and hospital where the research took place and all the participants and colleagues who made it successful. 


\section{References}

1.Lewis PM, Waddell JP. Fractured neck of femur: a review of three seminal papers and their implications to clinical management. Bone Jt Open. 2020;1(6):198-202. Epub 2020/11/24. doi: 10.1302/2633-1462.16.BJO-2020-0038.R1. PubMed PMID: 33225289; PubMed Central PMCID: PMCPMC7677723.

2.Swiontkowski MF, Winquist RA, Hansen ST, Jr. Fractures of the femoral neck in patients between the ages of twelve and forty-nine years. J Bone Joint Surg Am. 1984;66(6):837-46. Epub 1984/07/01. doi: 10.2106/00004623-198466060-00003. PubMed PMID: 6736085.

3.Pauyo T, Drager J, Albers A, Harvey EJ. Management of femoral neck fractures in the young patient: $A$ critical analysis review. World $J$ Orthop. 2014;5(3):204-17. Epub 2014/07/19. doi: 10.5312/wjo.v5.i3.204. PubMed PMID: 25035822; PubMed Central PMCID: PMCPMC4095012.

4.Levack AE, Gausden EB, Dvorzhinskiy A, Lorich DG, Helfet DL. Novel Treatment Options for the Surgical Management of Young Femoral Neck Fractures. J Orthop Trauma. 2019;33 Suppl 1:S33-S7. Epub 2018/12/13. doi: 10.1097/BOT.0000000000001368. PubMed PMID: 30540670; PubMed Central PMCID: PMCPMC6294468.

5.Ramallo DA, Kropf LL, Zaluski AD, Cavalcanti ADS, Duarte MEL, Guimaraes JAM. Factors Influencing the Outcome of Osteosynthesis in the Fracture of the Femoral Neck in Young Adult Patients. Rev Bras Ortop (Sao Paulo). 2019;54(4):408-15. Epub 2019/08/23. doi: 10.1016/j.rbo.2017.12.021. PubMed PMID: 31435107; PubMed Central PMCID: PMCPMC6701963.

6.Araujo TP, Guimaraes TM, Andrade-Silva FB, Kojima $\mathrm{KE}$, Silva Jdos S. Influence of time to surgery on the incidence of complications in femoral neck fracture treated with cannulated screws. Injury. 2014;45 Suppl 5:S36-9. Epub 2014/12/22. doi: 10.1016/S00201383(14)70019-1. PubMed PMID: 25528623.

7.Cch K, haseeb A, Ajit Singh V. Cannulated Screw Fixation For Femoral neck Fractures : A 5-year experience In A Single Institution. Malaysian
Orthopaedic Journal. 2014;8(2):14-21. doi: 10.5704/moj.1407.010.

8. Haidukewych GJ, Rothwell WS, Jacofsky DJ, Torchia ME, Berry DJ. Operative treatment of femoral neck fractures in patients between the ages of fifteen and fifty years. J Bone Joint Surg Am. 2004;86(8):1711-6. Epub 2004/08/05. doi: 10.2106/00004623200408000-00015. PubMed PMID: 15292419.

9. Frandsen PA, Andersen E, Madsen F, Skjodt T. Garden's classification of femoral neck fractures. An assessment of inter-observer variation. J Bone Joint Surg Br. 1988;70(4):588-90. Epub 1988/08/01. doi: 10.1302/0301-620X.70B4.3403602. PubMed PMID: 3403602.

10.Jain R, Koo M, Kreder HJ, Schemitsch EH, Davey JR, Mahomed NN. Comparison of early and delayed fixation of subcapital hip fractures in patients sixty years of age or less. J Bone Joint Surg Am. 2002;84(9):1605-12. Epub 2002/09/05. doi: 10.2106/00004623-200209000-00013. PubMed PMID: 12208917.

11.Ly TV, Swiontkowski MF. Management of femoral neck fractures in young adults. Indian J Orthop. 2008;42(1):3-12. Epub 2008/01/01. doi: 10.4103/0019-5413.38574. PubMed PMID: 19823648; PubMed Central PMCID: PMCPMC2759588.

12.Chan C, $\mathrm{Ng} \mathrm{W}$, Merican A. Ipsilateral femoral fracture non-union and delayed union treated by hybrid plate nail fixation and vascularized fibula bone grafting: a case report. Malays Orthop J. 2013;7(2):41-4. Epub 2013/07/01. doi: 10.5704/MOJ.1307.015. PubMed PMID: 25722826; PubMed Central PMCID: PMCPMC4341038.

13.Kainth GS, Yuvarajan P, Maini L, Kumar V. Neglected femoral neck fractures in adults. J Orthop Surg (Hong Kong). 2011;19(1):13-7. Epub 2011/04/27. doi: 10.1177/230949901101900104. PubMed PMID: 21519069.

14.Zhou L, Tan J, Xu B. [Treatment of femoral neck fracture with cannulated screw fixation in young adults]. Zhongguo Xiu Fu Chong Jian Wai Ke Za Zhi. 2007;21(3):275-7. Epub 2007/04/11. PubMed PMID: 17419210.

All correspondence to

Dr. Mohammad Mahbubur Rahman Khan Department of Orthopaedics National Institute of Traumatology \& orthopaedic rehabilitation, (NITOR) Sher-e-Bangla Nagor, Dhaka-1207 Bangladesh E-mail: mahbubdr37@hotmail.com 